\title{
Optic Nerve Head Optical Coherence Tomography Angiography Findings after Coronavirus Disease
}

\author{
Mojtaba Abrishami ${ }^{1}$, MD, MS; Ramin Daneshvar ${ }^{1}$, MD, MS; Zahra Emamverdian ${ }^{1}$, MSc; Nasser Shoeibi ${ }^{1}$, MD, MS \\ Shima Sedighi ${ }^{2}$, MD; Talieh Saeidi Rezvani ${ }^{3}$, PhD; Neda Saeedian ${ }^{4}$, MD; Saeid Eslami ${ }^{5}$, 6, 7 , PharmD, PhD \\ ${ }^{1}$ Eye Research Center, Mashhad University of Medical Sciences, Mashhad, Iran \\ ${ }^{2}$ Department of Emergency Medicine, University of Florida College of Medicine, Jacksonville, Jacksonville, FL, USA \\ ${ }^{3}$ Department of Education and Psychology, Ferdowsi University of Mashhad, Mashhad, Iran \\ ${ }^{4}$ Department of Internal Medicine, Faculty of Medicine, Mashhad University of Medical Sciences, Mashhad, Iran \\ ${ }^{5}$ Department of Medical Informatics, Faculty of Medicine, Mashhad University of Medical Sciences, Mashhad, Iran \\ ${ }^{6}$ Department of Medical Informatics, Amsterdam Public Health, Amsterdam UMC, University of Amsterdam, Amsterdam, The \\ Netherlands \\ ${ }^{7}$ Pharmaceutical Research Center, School of Pharmacy, Mashhad University of Medical Sciences, Mashhad, Iran
}

ORCID:

Mojtaba Abrishami: http://orcid.org/0000-0003-2001-7929

Ramin Daneshvar: http://orcid.org/0000-0002-0884-0907

Zahra Emamverdian: $h$ ttp://orcid.org/0000-0002-1659-1488

Nasser Shoeibi: http://orcid.org/0000-0003-3544-0105

Talieh Saeidi Rezvani: http://orcid.org/0000-0003-0460-8454

Neda Saeedian: http://orcid.org/0000-0003-2128-0315

Saeid Eslami: http://orcid.org/0000-0003-3755-1212

This study has been presented at the $8^{\text {th }}$ International Congress on OCT and OCT Angiography (ICOOR 2020 - Virtual) as an oral presentation.

\section{Abstract}

Purpose: To quantify the microvasculature density of the optic nerve head $(\mathrm{ONH})$ using optical coherence tomography angiography (OCTA) analysis in patients recovered from Coronavirus Disease 2019 (COVID-19).

Methods: In a comparative cross-sectional, observational study, patients recovered from COVID19 whose initial diagnosis was confirmed by a rRT-PCR of a nasopharyngeal sample were included in this study. OCTA of ONH was performed in included patients and normal controls. Vascular density (VD) of the all vessels (AV) and small vessels (SV) inside the disc and radial peripapillary capillary (RPC) network density were measured in COVID-19 recovered patients and compared with similar parameters in an age-matched group of normal controls.

Results: Twenty-five COVID-19 patients and twenty-two age-matched normal controls were enrolled in the study and one eye per participant was evaluated. The mean whole image SV VD in the COVID-19 group (49.31 \pm 1.93$)$ was not statistically significantly different from that in the control group (49.94 \pm . 2.22; $P=0.308$ ). A decrease in RPC VD was found in all AV and SV VD measured, which became statistically significant in whole peripapillary SV VD, peripapillary inferior nasal SV VD, peripapillary inferior temporal SV VD, peripapillary superior nasal SV VD, and grid-based AV VD inferior sector $(P<0.05)$. Inside disc SV VD in the COVID-19 group (49.43 $\pm 4.96)$ was higher than in the control group $(45.46 \pm 6.22)$ which was statistically significant $(P$ $=0.021)$.

Conclusion: Unremarkable decrease was found in $\mathrm{ONH}$ microvasculature in patients who had recovered from COVID-19. These patients may be at risk of ONH vascular complications. Increase in inner disc SV VD may be an indicator of ONH hyperemia and edema.

Keywords: Coronavirus Disease 2019 (COVID-19); Optic Nerve Head; Optical Coherence Tomography Angiography (OCTA); Radial Peripapillary Capillary Network; Severe Acute Respiratory Syndrome Corona Virus 2 (SARS-CoV-2)

J Ophthalmic Vis Res 2021; 16 (4): 592-601 


\section{INTRODUCTION}

Severe acute respiratory syndrome coronavirus 2 (SARS-CoV-2) is a new member of the Coronaviridae family of viruses, which can cause serious life-threatening respiratory illness, severe pneumonia, ${ }^{[1]}$ and even multiorgan failure. ${ }^{[2,3]}$ Various clinical presentations and fatal consequences of the associated disease, Coronavirus Disease 2019 (COVID-19), have been reported, but scarce reports regarding ocular manifestations are available. ${ }^{[4,5]}$

Angiotensin-converting enzyme (ACE)-2 is considered as the main receptor for SARS-CoV-2 infection. ${ }^{[6]}$ ACE2 as a member of the reninangiotensin-aldosterone system (RAAS) is present in different cell types including type II alveolar cells in the lung, arterial and venous endothelial cells, enterocytes of the small intestine, and smooth muscle cells of arterial vasculature of most organs. ${ }^{[7]}$ Its homologous enzyme is ACE, which is the main effector in the RAAS and ACE2 counterbalances and regulates its activity by reducing the amount of angiotensin-II and increasing Ang (1-7). ${ }^{[8]}$ ACE and ACE2 have been presented in the choroid and different cell types of the retina including retinal vascular endothelial cell, photoreceptor cells, Müller cells, and ganglion cells. ${ }^{\left[{ }^{[9]}\right.}$ Moreover, their expression in neurons and glial cells in the central nervous system (CNS) have been reported. ${ }^{[10]}$ Hence, it seems reasonable to expect ocular, and specifically optic nerve head $(\mathrm{ONH})$ and $\mathrm{CNS}$ manifestations of the SARS-CoV-2 infection.

The majority of reports on the ocular involvement in COVID-19 describe ocular surface manifestations including conjunctival congestion, chemosis, and conjunctivitis. ${ }^{[11]}$ Reports of the retinal findings are numerable. Marinho and colleagues described various retinal

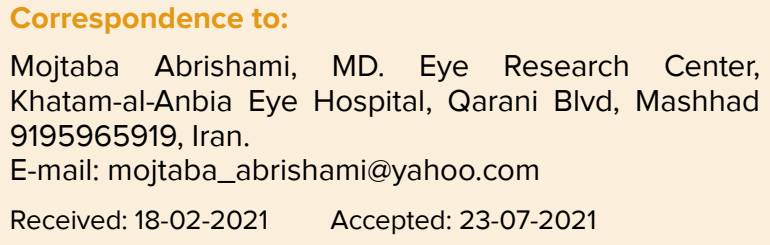

manifestations of COVID-19 like cotton wool spots and hemorrhages. ${ }^{[12]}$ In our previous report, we found decrease in macular vessel density in superficial and deep capillary peluxuses of the retina, using optical coherence tomography angiography (OCTA) in otherwise healthy relatively young patients. ${ }^{[13]}$ However, no similar report on $\mathrm{ONH}$ microvascular findings was avaiable in patients infected with SARS-CoV-2.

As the choroid, retina and nervous tissues could be targets of infection, because of binding of the virus to ACE2 receptor, and previous reports on ocular posterior segment lesions in COVID-19 individuals include nonspecific findings, like retinal hemorrhages or cotton wool spots, we aimed to evaluate the $\mathrm{ONH}$ microvasculature in relatively young and otherwise healthy patients recovered from COVID-19 and compare it with a normal group.

\section{METHODS}

\section{Study Participants}

A cross-sectional study was conducted at the Imam Reza General Hospital, Mashhad, Iran. Nurses and physicians working at Mashhad University of Medical Sciences (MUMS) with a definite diagnosis of COVID-19, confirmed by a positive test result of a nasopharyngeal swab sample real-time, reverse transcription-polymerase chain reaction, who recovered from the systemic symptoms at least two weeks prior to the enrolment, were included.

Detailed ocular and systemic histories were obtained from each participant and those with a history of autoimmune disease, migraine, diabetes mellitus, current pregnancy and breastfeeding, or any history of intraocular surgery were excluded. Additional exclusion criteria included absolute spherical refractive error $>5$ diopters and cylindrical refractive error $>2$ diopters, bestcorrected visual acuity $<20 / 20$, and evidence of glaucoma or clinically apparent retinal disease.

This is an open access journal, and articles are distributed under the terms of the Creative Commons Attribution-NonCommercial-ShareAlike 4.0 License, which allows others to remix, tweak, and build upon the work non-commercially, as long as appropriate credit is given and the new creations are licensed under the identical terms.

How to cite this article: Abrishami M, Daneshvar R, Emamverdian Z, Shoeibi N, Sedighi S, Rezvani TS, Saeedian N, Eslami S. Optic Nerve Head Optical Coherence Tomography Angiography Findings after Coronavirus Disease. J Ophthalmic Vis Res 2021;16:592-601. 
Those with ocular media opacity, like cataract or corneal haziness, preventing high-quality imaging or reduced OCTA scan quality (i.e., quality scan index $<7 / 10$ ) were also excluded from the analysis.

The age-matched control groups were healthy nurses and physicians employed by the MUMS who were imaged on the same OCTA machine at the Imam Reza Hospital in 2019; this group was recruited as part of an ongoing, longitudinal cohort study, PERSIAN Organizational Cohort study in MUMS.

Complete medical systemic history regarding the patients' COVID-19 symptoms, hospitalization, and disease course were recorded. Oxygen saturation at the time of examination was measured by a portable pulse oximeter.

\section{Image Acquisition and Analysis}

OCTA scans were performed with the AngioVue (RTVue XR Avanti, Optovue, Fremont, CA, USA; Software version 2018.0.0.14), an OCTA machine with A-scan-rate of 70,000 scans/sec. Each B scan line is repeated to evaluate the image decorrelation. Optic disc cubes, AngioDisc 4.5 $\times 4.5 \mathrm{~mm}$ HD scan (400 lines $\times 400$ A-scans) protocols, were scanned in the horizontal and vertical orthogonal directions. All measurements were primarily acquired using the automated default segmentation with the preset settings for the radial peripapillary capillary (RPC) network. The 3D Projection Artifact Removal by OCT 3D volume set were utilized.

All images were centered on the optic disc and displayed a scan quality index of at least $7 / 10$. Images with undesirable quality or image artifact were discarded and reacquired. All images in the study, mostly segmentation accuracy, were carefully reviewed by two authors (MA, RD) to ensure sufficient quality and resolution and any images with artifact significant enough to interfere with vessel density analysis were also excluded. For all subjects, cases or controls, only the data of the eye with better image quality was used for analysis.

To evaluate the RPC layer, a slab between the outer limit of the retinal nerve fiber layer (RNFL) and the internal limiting membrane were used. All images were checked for segmentation errors and manually adjusted before testing the vessel density. All vessels (AV), including both large and small vessels (SV), and SV vascular density (VD) were evaluated separately in the RPC layer. The whole image, inside disc area, in peripapillary whole, peripapillary superior and inferior hemifields, and eight segments SV RPC VD were reported. For the evaluation of AV VD, including both large vessels and SV, the whole image was divided into nine (three by three) grid-based sections, and AV VD in all sections was reported separately. Moreover, the whole image, inside the disc area, in peripapillary whole, peripapillary superior and inferior hemifields AV were reported.

\section{Statistical Analysis}

The normal distribution of variables was examined using the Shapiro-Wilk test and normality plots and homogeneity of variances were ascertained by Levene's test. Based on data distribution and type, either the independent-samples $t$-test, paired $t$-tests, or Mann-Whitney $U$ test were used for comparisons. Chi-square test and Fisher's exact test were used for categorical variables. The level of statistical significance was set at 0.05 . All statistical analyses were performed using the SPSS program for Windows, version 20 (IBM SPSS Statistics, IBM Corporation, Chicago, IL, USA).

\section{Ethical Considerations}

The study protocol adhered to the tenets of the Declaration of Helsinki. All participants provided written informed consent before enrollment and the ethical aspects of the study were approved by the Regional Committee on Medical Ethics at Mashhad University of Medical Sciences, Mashhad, Iran (IR.MUMS.REC.1399.104).

\section{RESULTS}

Twenty-five recovered COVID-19 patients (10 females, $40 \%$ ) with a mean age of $41.5 \pm 10.5$ years and 22 healthy normal controls (10 females, 45.4\%) with a mean age of $36.7 \pm 7.3$ years were enrolled in the study. Age $(P=0.086)$ and gender $(P=0.706)$ were not significantly different between the two groups. ONH parameters like cup-disc ratio and rim area were not different between the groups [Table 1]. None of the patients or controls had other systemic comorbidity except recent COVID-19 in last six months. 
Table 1. Comparison of optic nerve head parameters and age of COVID-19 patients eyes versus normal eyes

\begin{tabular}{lccc}
\hline & $\begin{array}{c}\text { Normal eyes }(\mathrm{n}=22) \text { Mean } \pm \\
\text { SD (Range) }\end{array}$ & $\begin{array}{c}\text { COVID-19 patients eyes (n= } \\
\text { 25) Mean } \pm \text { SD (Range) }\end{array}$ & $\begin{array}{c}P \text {-value } \\
(\text { Compare to } \\
\text { normal) }\end{array}$ \\
\hline Age (yr) & $41.5 \pm 10.5(24.00-53.00)$ & $36.7 \pm 7.3(25.00-61.00)$ & 0.086 \\
Cup/Disc Area Ratio & $0.14 \pm 0.09(0.00-0.33)$ & $0.12 \pm 0.10(0.00-0.35)$ & 0.415 \\
Cup/Disc Vertical Ratio & $0.37 \pm 0.18(0.00-0.60)$ & $0.30 \pm 0.21(0.00-0.61)$ & 0.283 \\
Cup/Disc Horizontal Ratio & $0.32 \pm 0.16(0.00-0.55)$ & $0.27 \pm 0.19(0.00-0.59)$ & 0.356 \\
Rim Area & $1.67 \pm 0.27(1.18-2.29)$ & $1.58 \pm 0.32(1.09-2.40)$ & 0.313 \\
Disc Area & $1.97 \pm 0.31(1.47-2.74)$ & $1.81 \pm 0.30(1.22-2.40)$ & 0.469 \\
Cup Volume & $0.09 \pm 0.18(0.00-0.87)$ & $0.06 \pm 0.08(0.00-0.34)$ & 0.151
\end{tabular}

RNFL, retinal nerve fiber layer; COVID-19, Coronavirus Disease 2019; SD, Standard Deviation

Table 2. Comparison of small vessels (SV) vessel density (VD) of COVID-19 patients eyes versus normal eyes

\begin{tabular}{|c|c|c|c|}
\hline & $\begin{array}{c}\text { COVID-19 patients eyes Mean } \\
\pm \text { SD (Range) }\end{array}$ & $\begin{array}{c}\text { Normal eyes Mean } \pm \text { SD } \\
\text { (Range) }\end{array}$ & $P$-value \\
\hline Whole Image - SV VD & $49.31 \pm 1.93(44.90-53.40)$ & $49.94 \pm 2.22(44.50-53.20)$ & 0.308 \\
\hline Inside Disc - SV VD & $S(37.70-56.40)$ & $45.46 \pm 6.22(24.80-53.00)$ & 0.021 \\
\hline Whole PeriPapillary - SV VD & $51.76 \pm 1.92(47.00-55.20)$ & $53.14 \pm 2.31(46.00-56.70)$ & 0.032 \\
\hline PeriPapillary Superior Hemi - SV VD & $52.01 \pm 2.16(46.90-55.70)$ & $53.12 \pm 2.90(44.40-57.10)$ & 0.148 \\
\hline PeriPapillary Inferior Hemi - SV VD & $51.79 \pm 3.31(44.90-62.00)$ & $53.16 \pm 2.13(47.70-57.90)$ & 0.095 \\
\hline PeriPapillary Nasal Superior - SV VD & $49.37 \pm 2.96(42.40-53.70)$ & $49.99 \pm 3.84$ ( $37.90-56.10)$ & 0.547 \\
\hline PeriPapillary Nasal Inferior - SV VD & $48.20 \pm 4.63(39.00-57.90)$ & $49.52 \pm 4.71(38.00-64.50)$ & 0.337 \\
\hline PeriPapillary Inferior Nasal - SV VD & $48.54 \pm 2.94(42.30-52.90)$ & $53.21 \pm 4.12(45.40-59.50)$ & $<0.001$ \\
\hline PeriPapillary Inferior Temporal - SV VD & $56.93 \pm 3.14(46.60-61.50)$ & $59.78 \pm 3.25(53.60-65.20)$ & 0.004 \\
\hline PeriPapillary Temporal Inferior - SV VD & $52.15 \pm 3.57(47.30-60.40)$ & $53.69 \pm 3(45.40-58.20)$ & 0.632 \\
\hline PeriPapillary Temporal Superior - SV VD & $55.86 \pm 4.02(44.20-61.30)$ & $55.96 \pm 4.50(44.50-63.80)$ & 0.889 \\
\hline PeriPapillary Superior Temporal - SV VD & $55.24 \pm 2.76(50.50-60.20)$ & $57.0 \pm 3.92(49.50-63.30)$ & 0.087 \\
\hline PeriPapillary Superior Nasal - SV VD & $49.03 \pm 3.3943 .60-55.50)$ & $51.14 \pm 3.72(41.20-58.70)$ & 0.049 \\
\hline
\end{tabular}

SV, small vessels; VD, vessel density; SD, Standard Deviation; COVID-19, Coronavirus Disease 2019

All patients were symptom-free for at least two weeks, and the mean recovery time interval between becoming symptom free and OCTA image acquisition was $20.3 \pm 2.9$ days (median: 18 days; authors range: 13-29 days). Past medical history was otherwise unremarkable for almost all of the patients and controls. None of the included subjects, COVID-19 cases or controls, endorsed a history of diabetes mellitus. Two COVID-19 patients had a history of grade 1 hypertension which was well controlled with medications or diet. Nine patients (36\%) had a history of hospitalization for
COVID-19. $\mathrm{O}_{2}$ saturation was in the normal range (94-99\%) in these patients and was not different from non-hospitalized patients $(P=0.513)$. The mean scan quality was $8.28 \pm 0.73$ in the COVID cases and $8.50 \pm 0.67$ in the normal controls $(P=$ 0.293). Right eye OCTA was analyzed for 11 patients and left eye for 14 patients.

The $4.5 \times 4.5 \mathrm{~mm}$ mean whole image SV VD in the COVID-19 group $(49.31 \pm 1.93)$ was not statistically different from that in the normal control group (49.94 \pm 2.22$)(P=0.308)$ although it seems to be lower in the COVID-19 recovered patients 
Table 3. Comparison of all vessels (AV), including both small and large vessels, vessel density (VD) of COVID-19 patients eyes versus normal eyes

\begin{tabular}{|c|c|c|c|}
\hline & $\begin{array}{c}\text { COVID-19 patients eyes Mean } \\
\pm \text { SD (Range) }\end{array}$ & $\begin{array}{c}\text { Normal eyes Mean } \pm \text { SD } \\
\text { (Range) }\end{array}$ & $P$-value \\
\hline Whole Image - AV VD & $56.08 \pm 1.89(52.50-60.20)$ & $56.44 \pm 2.29(51.40-59.10)$ & 0.566 \\
\hline Inside Disc - AV VD & $56.05 \pm 4.14$ (49.50-63.90) & $57.25 \pm 5.46(40.40-63.80)$ & 0.057 \\
\hline Whole Peripapillary - AV VD & $58.31 \pm 1.65(55.00-61.80)$ & $59.33 \pm 2.34(52.90-62.60)$ & 0.110 \\
\hline Peripapillary Superior Half - AV VD & $58.75 \pm 1.64(56.10-61.50)$ & $59.50 \pm 2.63(52.00-63.70)$ & 0.257 \\
\hline Peripapillary Inferior Half - AV VD & $57.90 \pm 2.08(53.20-62.60)$ & $59.11 \pm 2.30(53.90-63.60)$ & 0.066 \\
\hline Grid Based AV VD Supero temporal & $57.63 \pm 4.21(43.30-63.10)$ & $59.14 \pm 3.02$ (52.60-64.00) & 0.161 \\
\hline Grid Based AV VD Temporal & $56.46 \pm 3.08(46.60-62.00)$ & $57.01 \pm 3.37$ (50.40-61.50) & 0.565 \\
\hline Grid Based AV VD Infero temporal & $58.49 \pm 4.47(42.60-64.40)$ & $58.67 \pm 3.43(49.20-64.10)$ & 0.879 \\
\hline Grid Based AV VD Superior & $56.85 \pm 2.77$ (52.50-62.10) & $58.68 \pm 3.36(50.80-63.40)$ & 0.051 \\
\hline Grid Based AV VD Central & $58.10 \pm 4.56(50.00-64.60)$ & $60.35 \pm 3.23(49.00-64.40)$ & 0.061 \\
\hline Grid Based AV VD Inferior & $60.68 \pm 2.14$ (55.30-64.50) & $62.56 \pm 3.15(54.10-66.90)$ & 0.023 \\
\hline Grid Based AV VD Supero nasal & $51.71 \pm 4.19(43.90-58.20)$ & $52.09 \pm 3.36(43.60-59.90)$ & 0.739 \\
\hline Grid Based AV VD Nasal & $52.30 \pm 5.48(43.80-67.90)$ & $52.52 \pm 3.50(44.60-62.40)$ & 0.869 \\
\hline Grid Based AV VD Inferonasal & $50.29 \pm 3.91$ (44.40-59.80) & $50.35 \pm 3.84$ (41.60-58.10) & 0.903 \\
\hline
\end{tabular}

AV, all vessels; VD, vessel density; SD, Standard Deviation; COVID-19, Coronavirus Disease 2019

Table 4. Comparison of small vessels (SV) vessel density (VD) of hospitalized versus non-hospitalized/outpatients treated COVID-19 patients

\begin{tabular}{|c|c|c|c|}
\hline & $\begin{array}{c}\text { Outpatients }(\mathrm{n}=16) \text { Mean } \pm \text { SD } \\
\text { (Range) }\end{array}$ & $\begin{array}{c}\text { Hospitalized ( } n=9) \text { Mean } \pm \text { SD } \\
\text { (Range) }\end{array}$ & $P$-value \\
\hline Whole Image - SV VD & $46.77 \pm 4.74(29.70-53.60)$ & $46.45 \pm 4.08(40.30-54.00)$ & 0.860 \\
\hline Inside Disc - SV VD & $47.64 \pm 4.89(31.70-55.20)$ & $47.05 \pm 4.86(38.50-55.60)$ & 0.764 \\
\hline Whole PeriPapillary - SV VD & $48.76 \pm 4.26(34.70-56.10)$ & $47.10 \pm 4.48(41.70-53.20)$ & 0.344 \\
\hline PeriPapillary Superior Hemi - SV VD & $49 \pm 4.45(34.30-55.70)$ & $47.48 \pm 4.79(41.50-54.20)$ & 0.412 \\
\hline PeriPapillary Inferior Hemi - SV VD & $47.96 \pm 4.90(33.20-56.90)$ & $46.38 \pm 4.49$ (41.00-54.10) & 0.415 \\
\hline PeriPapillary Nasal Superior - SV VD & $48.90 \pm 4.64(34.40-55.90)$ & $47.64 \pm 5.11(42.60-55.90)$ & 0.512 \\
\hline PeriPapillary Nasal Inferior - SV VD & $49.70 \pm 3.60(43.40-55.30)$ & $49.85 \pm 3.03(45.70-55.70)$ & 0.910 \\
\hline PeriPapillary Inferior Nasal - SV VD & $49.59 \pm 3.65(42.80-54.90)$ & $49.71 \pm 2.86(46.20-54.90)$ & 0.930 \\
\hline PeriPapillary Inferior Temporal - SV VD & $49.79 \pm 3.69(43.90-55.60)$ & $50 \pm 3.30(45.20-56.40)$ & 0.884 \\
\hline PeriPapillary Temporal Inferior - SV VD & $32.07 \pm 5.11(18.10-40.20)$ & $34 \pm 9.32(14.10-45.40)$ & 0.463 \\
\hline PeriPapillary Temporal Superior - SV VD & $52.16 \pm 3.61(45.80-58.50)$ & $52.02 \pm 3.54(46.60-58.00)$ & 0.919 \\
\hline PeriPapillary Superior Temporal - SV VD & $52.16 \pm 3.64$ (46.30-58.20) & $51.82 \pm 3.38(46.70-57.50)$ & 0.809 \\
\hline PeriPapillary Superior Nasal - SV VD & $52.18 \pm 3.74(45.20-58.80)$ & $52.21 \pm 3.75(46.50-58.50)$ & 0.987 \\
\hline
\end{tabular}

SV, small vessels; VD, vessel density; SD, Standard Deviation; COVID-19, Coronavirus Disease 2019

[Table 2]. The $4.5 \times 4.5 \mathrm{~mm}$ mean whole image AV VD in the COVID-19 cohort (56.08 \pm 1.89$)$ was also not statistically significantly different with that in the controls (56.44 \pm 2.29$)(P=0.566)$; however, there was a tendency for lower values in the former group [Table 3; Figure 1].

Of note, whole peripapillary SV VD $(51.76 \pm 1.92$ vs $53.14 \pm 2.31 ; P=0.032$ ), peripapillary inferior nasal SV VD $(48.54 \pm 2.94$ vs $53.21 \pm 4.12 ; P<$ 
Table 5. Comparison of all vessels (AV), including both small and large vessels, vessel density (VD) of hospitalized versus nonhospitalized/outpatients treated COVID-19 patients

\begin{tabular}{|c|c|c|c|}
\hline & $\begin{array}{c}\text { Non-hospitalized }(n=16) \text { Mean } \\
\pm \text { SD (Range) }\end{array}$ & $\begin{array}{c}\text { Hospitalized ( } \mathrm{n}=9 \text { ) Mean } \pm \text { SD } \\
\text { (Range) }\end{array}$ & $\boldsymbol{P}$-value \\
\hline Whole Image - AV VD & $48.58 \pm 4.83(33.40-56.30)$ & $47.92 \pm 4.28(41.90-55.30)$ & 0.725 \\
\hline Inside Disc - AV VD & $49.54 \pm 4.86(31.90-56.40)$ & $48.12 \pm 3.95(41.80-54.90)$ & 0.444 \\
\hline Whole Peripapillary - AV VD & $48.51 \pm 4.24(35.10-56.50)$ & $46.68 \pm 4.35(41.60-53.00)$ & 0.292 \\
\hline Peripapillary Superior Half - AV VD & $45.28 \pm 4.34(30.80-53.40)$ & $43.71 \pm 4.04(38.60-49.70)$ & 0.362 \\
\hline Peripapillary Inferior Half - AV VD & $52.93 \pm 4.21(40.40-59.20)$ & $50.60 \pm 4.93(43.90-57.60)$ & 0.197 \\
\hline Grid Based AV VD Superotemporal & $52.41 \pm 3.54(45.30-57.80)$ & $52.68 \pm 3.02(48.80-56.80)$ & 0.843 \\
\hline Grid Based AV VD Temporal & $51.53 \pm 4.19(43.90-58.20)$ & $51.16 \pm 4.06(45.30-58.60)$ & 0.824 \\
\hline Grid Based AV VD Inferotemporal & $52.93 \pm 3.81(46.50-59.80)$ & $52.22 \pm 3.08(46.70-57.40)$ & 0.622 \\
\hline Grid Based AV VD Superior & $51.79 \pm 3.91(44.40-58.30)$ & $51.97 \pm 4.43(45.60-59.20)$ & 0.911 \\
\hline Grid Based AV VD Central & $49.87 \pm 6.10(39.50-62.90)$ & $49.52 \pm 3.44(43.00-54.00)$ & 0.874 \\
\hline Grid Based AV VD Inferior & $49.88 \pm 6.07(40.30-63.50)$ & $49.07 \pm 3.21(43.90-53.70)$ & 0.712 \\
\hline Grid Based AV VD Superonasal & $49.77 \pm 6.24(38.60-62.20)$ & $49.95 \pm 3.81(42.00-54.30)$ & 0.937 \\
\hline Grid Based AV VD Nasal & $53.35 \pm 5.56(42.10-63.60)$ & $53.38 \pm 3.78(46.50-58.00)$ & 0.986 \\
\hline Grid Based AV VD Inferonasal & $48.56 \pm 6.64(39.30-62.90)$ & $48.66 \pm 3.73(43.30-55.10)$ & 0.967 \\
\hline
\end{tabular}

AV, all vessels; VD, vessel density; SD, Standard Deviation; COVID-19, Coronavirus Disease 2019

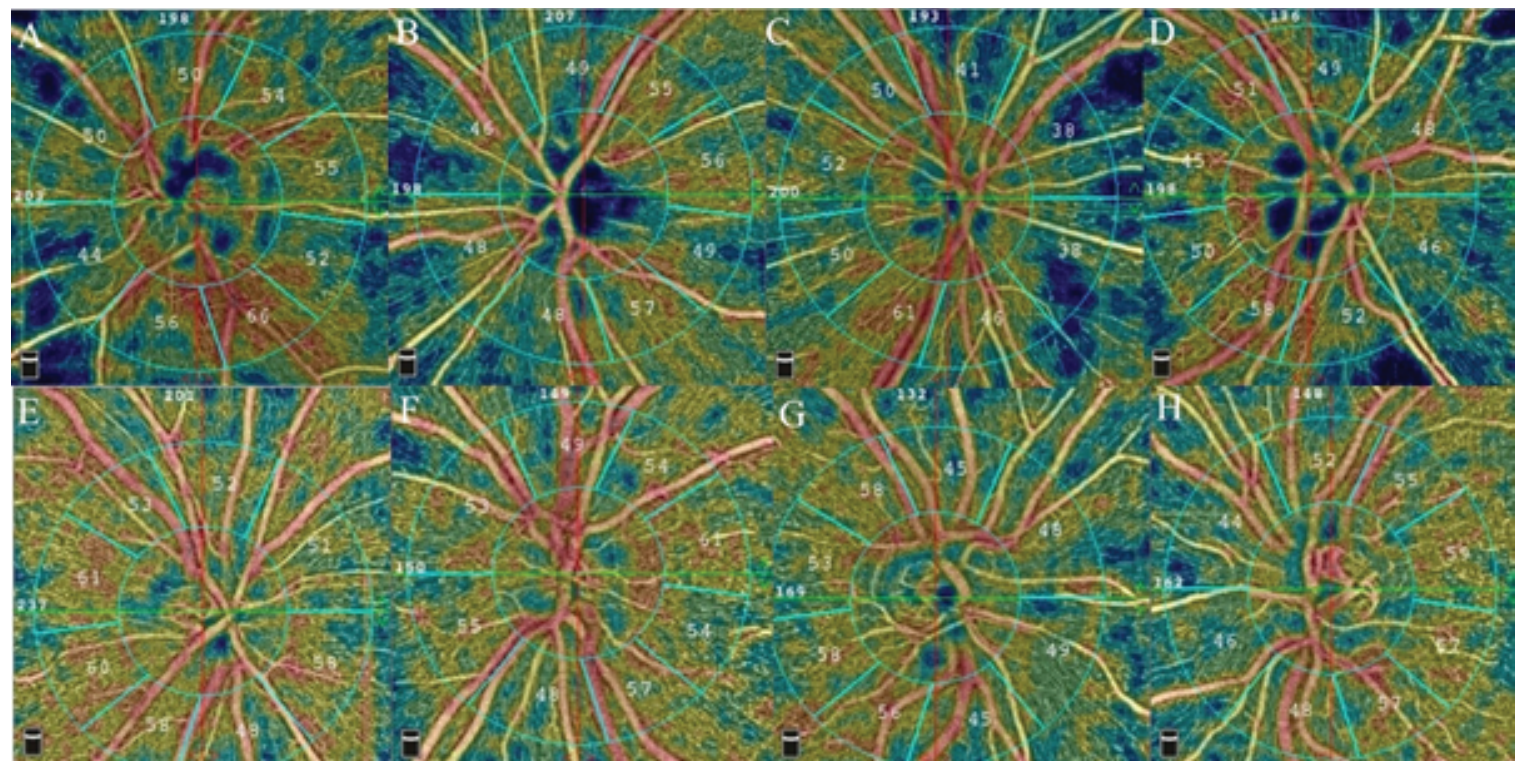

Figure 1. En-face optical coherence tomography angiograms (OCTA) segmented at the level of the radial peripapillary capillary (RPC) network from four recovered COVID-19 patients (A-D) versus four age-matched normal controls (E-H). Note the remarkable flow deficits present in the en-face angiograms from the COVID cases.

0.001), peripapillary inferior temporal SV VD (56.93 \pm 3.14 vs $59.78 \pm 3.25 ; P=0.004)$, and gridbased AV VD in inferior sector $(60.68 \pm 2.14 \mathrm{vs}$ $62.56 \pm 3.15 ; P=0.023$ ) were significantly lower in COVID-19 patients, compared with normal controls. In addition, in all other parameters, except inside disc SV VD, COVID-19 patients had lower VD in AV and SV VD, but the differences were not statistically significant. Inside disc SV VD in COVID-19 patients $(49.43 \pm 4.96)$ was higher than the inside disc SV VD in the normal control group (45.46 \pm 6.22$)$, which was statistically significant $(P=0.021)$. 
Moreover, subgroup analysis between hospitalized and outpatient treated patients revealed no statistically significant difference between two groups although unremarkable lower values were observed in hospitalized patients versus outpatients [Tables 4 and 5].

\section{DISCUSSION}

In the present study, we used OCTA to determine the VD in the ONH and the RPC layer of optic disc in a relatively young, mild involvement, without other comorbidity and minority hospitalized, cohort of recovered COVID-19 patients and compare it with an age-matched normal control group. Except inside disc SV VD which was higher in the COVID19 patients, in all RPC measured SV and AV VD recovered COVID-19 patients showed lower values, which became statistically significant in whole peripapillary SV VD, peripapillary inferior nasal SV VD, peripapillary inferior temporal SV VD, and grid-based AV VD Inferior sector. In other segments of peripapillary SV VD and grid-based sectors of $A V V D$, vessel densities tend to be lower in the COVID group but this did not reach statistical significance. In a subgroup analysis, in hospitalized patients we found in all RPC measured SV and AV VD unremarkable lower values versus outpatient treated COVID-19 patients which were not statistically significant.

In an autopsy study, Casagrande and associates detected SARS-CoV-2 viral particles in the retina of patients who had deceased due to COVID19. ${ }^{[14]}$ Presence of ACE2 receptors in CNS and various layers of the retina and choroid have been reported; $[9,10]$ hence, pathologic changes in the ocular tissues, and especially in $\mathrm{ONH}$ and retina, may be expected.

In a recent case series using Zeiss Cirrus 5000 HD OCT Angioplex, RPC plexus perfusion density was lower in 80 COVID-19 recovered patients compared to 30 controls. Moreover, patients treated with lopinavir, ritonavir, or antiplatelet therapy during admission had lower RPC flow index and RPC perfusion density. ${ }^{[15]}$ It indicates probable ONH involvement in COVID-19. Moreover, GuillainBarré syndrome and Miller-Fisher-like syndrome have also been reported in association with SARS-CoV-2 infection. ${ }^{[16,17]}$ In recent studies, SARS-CoV-2 potential for neuroinvasion has been suggested. ${ }^{[18]}$ It seems that in-line with the previous reports of retinitis and optic neuritis induced by coronaviruses in animal models, ${ }^{[19]}$ and the proposed neuroinvasion hypothesis, SARS-CoV-2 can cause neuro-inflammation and neuro-infection in humans too. Besides the neurologic involvements, as retinal ganglion cells, Müller cells, and blood vessels are potential targets of the virus, the $\mathrm{ONH}$ and retinal findings in COVID-19 are well anticipated. Vascular changes can be either primary or secondary to alternations in the hemodynamic demands of the inflamed and damaged tissues.

Macular OCTA analysis also found similar results. In another study by our group, using Optovue AngioVue Imaging System, macular VD was decreased in COVID-19 patients compared with normal controls. ${ }^{[13]}$ In another similar study in Turkey with a same machine, parafoveal VD in the superior and nasal quadrants of the superficial capillary plexus and in all quadrants of the deep capillary plexus were significantly lower in COVID-19 patients. ${ }^{[20]}$ Moreover, in a case-control study in patients stratified to mild, moderate, and severe COVID-19 disease activity, and normal controls, patients with moderate and severe disease had decreased macular VD as compared with control subjects or even those who were asymptomatic or paucisymptomatic. ${ }^{[21]}$ It has been proposed that SARS-CoV-2 infection, as a systemic multi-organ infection, may affect retinal vasculature beside other organs and marks retinal microvasculature. ${ }^{[22]}$

OCTA analysis is an invaluable tool in the evaluation of vascular changes in the retina and $\mathrm{ONH}$ for diagnosis, staging, and monitoring in glaucoma. ${ }^{[23,24]}$ In addition, in several neurologic conditions, including preclinical Alzheimer's disease, OCTA was found to be helpful. ${ }^{[25]}$ In other neurodegenerative diseases and even mild cognitive disorders, OCTA has been proposed as an additional biomarker for the early diagnosis and disease activity monitoring. ${ }^{[26,27]}$ In this study, we found that $\mathrm{ONH}$ microvasculature was somewhat decreased compared to the age-matched controls. In all segments, VD was numerically decreased in these comparative analyses, although the differences were statistically significant in some segments.

An intriguing finding in our study was the higher SV inside disc VD, which was statistically higher than normal controls. Previously, it has been reported that $\mathrm{ONH}$, nerve fiber layer thickness, is 
increased in COVID 19 recovered patients. ${ }^{[28,29]}$ In a case report, acute bilateral optic neuritis has been reported in a 44-year-old Hispanic male patient with no past medical history. Multimodal ocular, orbit, and CNS imaging and paraclinic evaluations were performed to determine the possibility of demyelinating or other autoimmune disease and these evaluations were negative as well as other laboratory assessment. Therefore, it has been concluded that his infection with COVID-19 virus has triggered his immune system to present $\mathrm{ONH}$ findings. ${ }^{[30]}$ Besides our findings, increase in SV VD inside the disc area, which is in contrary to RPC VD findings, may be associated with $\mathrm{ONH}$ edema and hyperemia, indicating potential optic nerve involvement in COVID-19 patients, in line with our previous findings of nerve fiber layer thickening in COVID19 patients.

Essentially, the retina and optic nerve are considered to be intraorbital extensions of the CNS, so evaluation of the retinal, and more specifically $\mathrm{ONH}$ changes, may help us to identify the CNS disease as well. Indeed, $\mathrm{ONH}$ and $\mathrm{pRNFL}$ changes have been already reported in patients with CNS pathologies like Alzheimer, multiple sclerosis, and diabetic polyneuropathy. ${ }^{[31-33]}$ In a recent review, neuroophthalmic manifestations of COVID-19 was divided to afferent and efferent manifestations. ${ }^{[34]}$ The examples of the afferent complications include papilledema, optic neuritis, papillophlebitis, and even vision loss due to stroke, while the efferent complications include ocular myasthenia gravis, cranial neuropathies, Miller Fisher syndrome, and Adie's pupils. ${ }^{[34]}$ These presentations magnifies the importance of $\mathrm{ONH}$ evaluations in COVID19 patients, as these presentations beyond ophthalmic importance which may affect visual function of patients, should be considered as CNS involvement which may be more disabling or even fatal.

Our control group was recruited from healthy personnel of MUMS, as part of a longitudinal cohort study, PERSIAN Organizational Cohort study in MUMS. ${ }^{[35]}$ The controls were evaluated and OCTA images were acquired to build a local normal OCTA normative database and cohort analysis. The individuals in the control group were examined when no COVID-19 cases were formally reported in Iran in 2019. Therefore, there is no chance for presence of any symptom-free patient among our control group.

This study has several limitations. First, OCTA images were acquired during the recovery of the disease and not during the acute phase when the systemic condition was active. Second, longitudinal analysis of the patients was not performed. Third, we had a limited sample size, which can explain the lack of statistical significance in some comparisons. A largerscale study with OCTA performed during the symptomatic phase of the disease, followed by repeat imaging at fixed intervals, would provide valuable information regarding both the short and long-term effects of COVID-19 on the $\mathrm{ONH}$ vascular system.

To the best of our knowledge, it's the first report of ONH OCTA findings in patients with a history of COVID-19. The clinical relevance of our finding is unclear, as the patients were all asymptomatic with $20 / 20$ vision at the time of this analysis. This can indicate the acute inflammatory phase of the ocular involvement and the associated vasodilation. It is noteworthy that the systemic and ocular disease phases can be unparalleled and occur at different times. Nevertheless, our findings in a relatively young group of COVID-19 confirmed patients who had no other comorbidity, and the comparison with an age-matched normal control group, similarly imaged, is novel and may highlight the importance of continued vigilance for the detection of nervous tissue and ocular complications associated to COVID-19 as the pandemic evolves.

In conclusion, our study demonstrated ONH VD alterations in patients with a history of COVID19 and without other comorbidities, including a decrease in AV and SV RPC VD. These findings beside previous microvascular retinal findings in these patients indicate potential retinal and $\mathrm{ONH}$ ischemic changes, which may be a manifestation of CNS potential vascular involvement. Moreover, increase in inside disc SV VD may be an indicator of $\mathrm{ONH}$ hyperemia and edema.

\section{Acknowledgement}

The authors would like to thank Abbas Saberi and Hojjat Salmani at Mashhad PERSIAN Cohort Center, for their kind assistance with this research project. It is a pleasure for them to also acknowledge the kind support of Capt. Mehdi Madadi. 


\section{Financial Support and Sponsorship}

The authors would like to acknowledge the financial support of the Vice-Chancellor of Research of Mashhad University of Medical Sciences for this research project (code: 990069). The funding organization had no role in the design or conduct of this study.

\section{Conflicts of Interest}

The authors declare no potential conflicts of interest for the research, authorship, and/or publication of this article.

\section{REFERENCES}

1. Ahn DG, Shin HJ, Kim MH, Lee S, Kim H-S, Myoung J, et al. Current status of epidemiology, diagnosis, therapeutics, and vaccines for novel Coronavirus disease 2019 (COVID19). J Microbiol Biotechnol 2020;30:313-324.

2. Gheblawi M, Wang K, Viveiros A, Nguyen Q, Zhong J-C, Turner AJ, et al. Angiotensin-converting enzyme 2: SARSCoV-2 receptor and regulator of the renin-angiotensin system: celebrating the 20th anniversary of the discovery of ACE2. Circ Res 2020;126:1456-1474.

3. Huang C, Wang Y, Li X, Ren L, Zhao J, Hu Y, et al. Clinical features of patients infected with 2019 novel coronavirus in Wuhan, China. Lancet 2020;395:497-506.

4. Li JO, Lam DSC, Chen Y, Ting DSW. Novel Coronavirus disease 2019 (COVID-19): the importance of recognising possible early ocular manifestation and using protective eyewear. Br J Ophthalmol 2020;104:297-298.

5. Mungmungpuntipantip R, Wiwanitkit V. Ocular manifestation, eye protection, and COVID-19. Graefes Arch Clin Exp Ophthalmol 2020;258:1339.

6. Wan Y, Shang J, Graham R, Baric RS, Li F. Receptor recognition by the novel Coronavirus from Wuhan: an analysis based on decade-long structural studies of SARS Coronavirus. J Virol 2020;94:e00127-e00120.

7. Hamming I, Timens W, Bulthuis ML, Lely AT, Navis $G$, van Goor $H$. Tissue distribution of ACE2 protein, the functional receptor for SARS coronavirus. A first step in understanding SARS pathogenesis. J Pathol 2004;203:631-637.

8. Chamsi-Pasha MA, Shao Z, Tang WH. Angiotensinconverting enzyme 2 as a therapeutic target for heart failure. Curr Heart Fail Rep 2014;11:58-63.

9. Choudhary R, Kapoor MS, Singh A, Bodakhe SH. Therapeutic targets of renin-angiotensin system in ocular disorders. J Curr Ophthalmol 2017;29:7-16.

10. Zhou Z, Kang $\mathrm{H}$, Li S, Zhao X. Understanding the neurotropic characteristics of SARS-CoV-2: from neurological manifestations of COVID-19 to potential neurotropic mechanisms. J Neurol 2020;267:2179-2184.

11. Abrishami M, Tohidinezhad F, Daneshvar R, Omidtabrizi A, Amini M, Sedaghat A, et al. Ocular manifestations of hospitalized patients with COVID-19 in northeast of Iran. Ocul Immunol Inflamm 2020;28:739-744.
12. Marinho PM, Marcos AAA, Romano AC, Nascimento $H$, Belfort R Jr. Retinal findings in patients with COVID-19. Lancet 2020;395:1610.

13. Abrishami M, Emamverdian Z, Shoeibi N, Omidtabrizi A, Daneshvar R, Rezvani TS, et al. Optical coherence tomography angiography analysis of the retina in patients recovered from COVID-19: a case-control study. Can J Ophthalmol 2021;56:24-30.

14. Casagrande M, Fitzek A, Puschel K, Aleshcheva G, Schultheiss H-P, Berneking L, et al. Detection of SARSCoV-2 in human retinal biopsies of deceased COVID-19 patients. Ocul Immunol Inflamm 2020;28:721-725.

15. Savastano A, Crincoli E, Savastano MC, Younis S, Gambini G, De Vico U, et al. Peripapillary retinal vascular involvement in early post-COVID-19 patients. J Clin Med 2020;9:2895.

16. Su XW, Palka SV, Rao RR, Chen FS, Brackney CR, Cambi F. SARS-CoV-2-associated Guillain-Barre syndrome with dysautonomia. Muscle Nerve 2020;62:E48-E49.

17. Fernandez-Dominguez J, Ameijide-Sanluis E, GarciaCabo C, Garcia-Rodriguez R, Mateos V. Miller-Fisher-like syndrome related to SARS-CoV-2 infection (COVID 19). J Neurol 2020;267:2495-2496.

18. DosSantos MF, Devalle S, Aran V, Capra D, Roque NR, de Mattos Coelho-Aguiar J, et al. Neuromechanisms of SARSCoV-2: a review. Front Neuroanat 2020;14:37.

19. Seah I, Agrawal R. Can the Coronavirus disease 2019 (COVID-19) affect the eyes? A review of Coronaviruses and ocular implications in humans and animals. Ocul Immunol Inflamm 2020;28:391-395.

20. Turker IC, Dogan CU, Guven D, Kutucu OK, Gul C. Optical coherence tomography angiography findings in patients with COVID-19. Can J Ophthalmol 2021;56:83-87.

21. Zapata MÁ, Banderas García S, Sánchez-Moltalvá A, et al. Retinal microvascular abnormalities in patients after COVID-19 depending on disease severity [published online ahead of print, $2020 \mathrm{Dec}$ 16]. Br J Ophthalmol 2020;bjophthalmol-2020-317953.

22. Sim SS, Cheung CMG. Does COVID-19 infection leave a mark on the retinal vasculature? Can J Ophthalmol 2021;56:4-5.

23. Ma ZW, Qiu WH, Zhou DN, Yang WH, Pan XF, Chen $H$. Changes in vessel density of the patients with narrow antenior chamber after an acute intraocular pressure elevation observed by OCT angiography. BMC Ophthalmol 2019;19:132.

24. Lommatzsch C, Rothaus K, Koch JM, Heinz C, Grisanti S. Vessel density in OCT angiography permits differentiation between normal and glaucomatous optic nerve heads. Int J Ophthalmol 2018;11:835-843.

25. van de Kreeke JA, Nguyen HT, Konijnenberg E, Tomassen $\mathrm{J}$, den Braber A, Kate MT, et al. Optical coherence tomography angiography in preclinical Alzheimer's disease. Br J Ophthalmol 2020;104:157-161.

26. Pellegrini M, Vagge A, Ferro Desideri LF, Bernabei F, Triolo G, Mastropasqua R, et al. Optical coherence tomography angiography in neurodegenerative disorders. J Clin Med 2020;9:1706.

27. Criscuolo C, Cennamo G, Montorio D, Carotenuto A, Strianese A, Salvatore $E$, et al. Assessment of retinal vascular network in amnestic mild cognitive impairment 
by optical coherence tomography angiography. PLoS One 2020;15:e0233975.

28. Abrishami M, Daneshvar R, Emamverdian Z, Tohidinezhad F, Eslami S. Optic nerve head parameters and peripapillary retinal nerve fiber layer thickness in patients with Coronavirus disease 2019. Ocul Immunol Inflamm 2021 Feb:1-4.

29. Burgos-Blasco B, Guemes-Villahoz N, Donate-Lopez J, Vidal-Villegas B, Garcia-Feijoo J. Optic nerve analysis in COVID-19 patients. J Med Virol 2020;93:190-191.

30. Sawalha K, Adeodokun S, Kamoga GR. COVID-19-induced acute bilateral optic neuritis. J Investig Med High Impact Case Rep 2020;8:2324709620976018.

31. Cabrera DeBuc D, Gaca-Wysocka M, Grzybowski A, Kanclerz P. Identification of retinal biomarkers in Alzheimer's disease using optical coherence tomography: recent insights, challenges, and opportunities. J Clin Med 2019;8:996.

32. Pietroboni AM, Carandini T, Dell'Arti L, Bovis F, Colombi $A$, De Riz MA, et al. Evidence of retinal anterograde neurodegeneration in the very early stages of multiple sclerosis: a longitudinal OCT study. Neurol Sci 2020;41:3175-3183.

33. Salvi L, Plateroti P, Balducci S, Bollanti L, Conti FG, Vitale $\mathrm{M}$, et al. Abnormalities of retinal ganglion cell complex at optical coherence tomography in patients with type 2 diabetes: a sign of diabetic polyneuropathy, not retinopathy. J Diabetes Complications 2016;30:469-476.

34. Tisdale AK, Dinkin M, Chwalisz BK. Afferent and efferent neuro-ophthalmic complications of Coronavirus disease 19. J Neuroophthalmol 2021;41:154-165.

35. Tohidinezhad F, Khorsand A, Zakavi SR, Rezvani R, Zarei-Ghanavati S, Abrishami M, et al. The burden and predisposing factors of non-communicable diseases in Mashhad University of Medical Sciences personnel: a prospective 15-year organizational cohort study protocol and baseline assessment. BMC Public Health 2020;20:1637. 